\title{
Safety and efficacy of low-dose rhBMP-2 use for anterior cervical fusion
}

\author{
Stephen K. Mendenhall, MD, ${ }^{1}$ Blake H. Priddy, MD, ${ }^{1}$ Jean-Pierre Mobasser, MD, ${ }^{2,3}$ and \\ Eric A. Potts, MD2,3
}

1Department of Neurological Surgery, Indiana University School of Medicine, Indianapolis; ${ }^{2}$ Goodman Campbell Brain and Spine, Carmel; and ${ }^{3}$ Ascension St. Vincent Hospital, Indianapolis, Indiana

\begin{abstract}
OBJECTIVE The use of recombinant human bone morphogenetic protein 2 (rhBMP-2) in routine anterior cervical fusion (ACF) is controversial. Early reports described high complication rates. A variety of dosing regimens ranging from 0.6 to $2.1 \mathrm{mg}$ per level fused have been reported. The authors hypothesized that the high amounts of rhBMP-2 used in these studies led to the high complication rates observed; therefore, they set out to evaluate the safety and efficacy of lowdose rhBMP-2 for use in ACFs.
\end{abstract}

METHODS Patient inclusion criteria were 1) age 18 to 70 years; 2) initial stand-alone ACF construct; 3) fusion augmentation with rhBMP-2; and 4) at least 1 year of radiographic follow-up. A successful fusion was defined by either 1) lateral flexion-extension radiographs with less than $1 \mathrm{~mm}$ of movement across the fused spinous processes, or 2) bone bridging at least half of the fusion area originally achieved by surgery on fine-cut CT. Patient demographics, perioperative data, and postoperative complications were recorded.

RESULTS A total of 198 patients met the inclusion criteria and were included for analysis. Sixty-two patients (31\%) were smokers. The median number of levels fused was 2 (IQR 1.25). The mean dose of rhBMP-2 was $0.50 \pm 0.09 \mathrm{mg}$ per level. Twenty-two (11\%) patients experienced dysphagia. Eleven (6\%) patients experienced cervical swelling. Two (1\%) patients returned to the operating room (OR) for postoperative hematoma. One $(0.5 \%)$ patient returned to the OR for seroma. Two (1\%) patients experienced pseudarthrosis requiring a posterior fusion. Three (2\%) patients experienced a new postoperative neurological deficit that had recovered by last the follow-up. Overall, $190(96 \%)$ patients experienced solid arthrodesis over an average of 15 months of follow-up. There was no difference in fusion rates between patients who were either smokers or nonsmokers ( $p=0.7073$ ).

CONCLUSIONS The use of low-dose rhBMP-2 safely and effectively augmented anterior cervical arthrodesis. The low-dose protocol assessed in this study appeared to significantly reduce complications associated with rhBMP-2 use in ACF compared with the literature. The authors have determined that using low-dose rhBMP-2 in patients who are smokers, those with multilevel ACFs, or others at high risk of developing pseudarthrosis is recommended.

https://thejns.org/doi/abs/10.3171/2021.3.FOCUS2171

KEYWORDS bone morphogenetic protein; spine; anterior; cervical

$\mathrm{R}$ ECOMBINANT human bone morphogenetic protein (BMP)-2 (rhBMP-2) was first evaluated in 1997 in a prospective randomized trial under an FDAapproved investigational device exemption. ${ }^{1}$ In that study, rhBMP-2 was placed on an absorbable collagen sponge and placed into a titanium interbody fusion device. The authors concluded that fusion occurred more reliably in patients who received rhBMP-2. ${ }^{1}$ In a multicenter followup study, INFUSE Bone Graft/LT-CAGE lumbar tapered fusion device (Medtronic) and autograft were compared for clinical and radiographic fusion following anterior lumbar interbody fusion (ALIF). ${ }^{2}$ The INFUSE (containing rhBMP-2) group achieved higher fusion rates without the effects of donor-site discomfort that were found in the autograft group. ${ }^{2}$ Because of this study, Medtronic was granted FDA approval for the use of rhBMP-2 for ALIF. The clinical results indicating superior fusion rates using rhBMP-2 has led to increased off-label usage ${ }^{3}$ in patients with known risk factors for nonunion such as smoking, diabetes, and obesity. 
The use of rhBMP-2 in anterior cervical fusion (ACF) is controversial. In 2006, Shields et al. ${ }^{4}$ reported high complication rates in patients undergoing $\mathrm{ACF}$ using high-dose rhBMP-2 (2.1 mg per level). At this dose, $23.2 \%$ (35/151) of patients experienced complications, including 15 patients with hematoma/seroma and 13 patients who experienced protracted issues with swallowing/breathing or swelling without hematoma. ${ }^{4}$ In June 2008, Tumialán et al. ${ }^{5}$ reported soft-tissue swelling in a series of 200 patients undergoing ACF augmented with rhBMP-2. During this study, they reduced the dosage twice, initially starting with $2.1 \mathrm{mg}$ per level, reduced to $1.05 \mathrm{mg}$ per level, and further reduced a second time to $0.7 \mathrm{mg}$ per level. ${ }^{5} \mathrm{Al}-$ though the authors did not find a significant difference in dysphagia/swelling between the study group and historical controls - there was not a sufficient number of patients to compare complications between different rhBMP-2 doses-they concluded that the complication rates increased with increasing rhBMP-2 concentrations. ${ }^{5}$ Despite this report, in July 2008 the FDA issued a public health notification detailing the risks of rhBMP-2 in the anterior cervical spine. ${ }^{6}$ To further complicate the picture, the only prospective randomized trial evaluating rhBMP-2 in ACF found that there was no increase in the complications rate. ${ }^{7}$ Given the current evidence in the scientific literature it is difficult to assess the true risk of rhBMP-2 usage in anterior cervical surgery.

In this study, we set out to evaluate the safety and efficacy of low-dose rhBMP-2 for use in ACFs. We hypothesized that the high dosages of rhBMP-2 used in prior studies led to the high complication rates observed, and that a low dose should lead to significantly lower complication rates than historical controls, and comparable rates of arthrodesis for patients who would otherwise have lower than average expected arthrodesis rates (e.g., smokers).

\section{Methods \\ Patient Selection}

We performed a retrospective chart review that was approved by the St. Vincent and Indiana University institutional review boards. Patient consent was not required for this retrospective study. Patient inclusion criteria were 1) age 18 to 70 years; 2 ) initial stand-alone ACF construct; 3 ) fusion augmentation with rhBMP-2; and 4) at least 1 year of radiographic follow-up. Patients not meeting inclusion criteria were excluded from the study. Patient demographics, perioperative data, and postoperative complications were recorded for all included patients.

\section{Evaluation of Dysphagia}

All patients received a postoperative phone call within 1 week of surgery and were specifically questioned about swallowing difficulty and neck swelling. If significant swelling or swallowing issues were encountered, patients were started on oral corticosteroids and evaluated at the 4-week postoperative wound check, or sooner, depending on the severity of symptoms. No patients received prophylactic perioperative oral, intravenous, or topical corticosteroids.

\section{Dosing of rhBMP-2}

The rhBMP-2 dose was determined by graft size. BMP volume in milliliters was matched with the internal volume of the interbody spacer. The size of the rhBMP-2 kit and the percentage of sponge used for each case was recorded in the operative report and used to calculate the milligrams of rhBMP-2 per level. The xx-small rhBMP-2 kit contained $1.05 \mathrm{mg} / 0.7 \mathrm{ml}$ and the $\mathrm{x}$-small kit contained $2.1 \mathrm{mg} / 1.4 \mathrm{ml} .^{8}$

\section{Evaluation of Fusion}

All patients meeting inclusion criteria had radiographic evaluation of fusion at approximately 1 year postoperatively. Spinal fusion was evaluated with dynamic radiographs or CT. Successful fusion was defined by either 1) lateral flexion-extension radiographs with less than $1 \mathrm{~mm}$ of movement across the fused spinous processes, or 2) bone bridging at least half of the fusion area originally achieved by surgery on fine-cut CT. ${ }^{9-11}$

\section{Statistical Analysis}

Parametric data are given as the mean \pm SD and compared using the Student t-test. Nonparametric data are given as median (IQR) and compared by the Mann-Whitney U-test. Nominal data were compared with the chi-square test. Probability values $<0.05$ were considered statistically significant. All statistical analysis was performed using IBM SPSS Statistics version 24.0 (IBM Corp.).

\section{Results}

\section{Patient Demographics}

A total of 216 patients underwent ACF with rhBMP-2 augmentation from 2004 to 2015. All surgeries were performed by the senior authors (E.A.P. and J.P.M.). Eighteen patients were excluded because of loss to follow-up, leaving a total of 198 (91.7\%) patients for analysis with a mean age of $55 \pm 10$ years. Ninety-five (48\%) patients were male. The average follow-up was $15 \pm 10$ months. The median Charlson Comorbidity Index (CCI) score was 1 (IQR 0-2). Sixty-two (31\%) patients were smokers. Fifteen (8\%) patients used nonsteroidal antiinflammatory drugs (Table 1).

\section{Surgical Characteristics}

Senior author E.A.P. used a noncontained device while J.P.M. used a contained device for anterior cervical discectomy and fusion (ACDF). Both used a noncontained device for corpectomy. Patients underwent the following procedures: 1-level ACDF ( $\mathrm{n}=78,40 \%)$, 2-level ACDF $(\mathrm{n}=47,23 \%), 3$-level ACDF $(\mathrm{n}=26,13 \%)$, 4-level ACDF $(\mathrm{n}=4,2 \%), 1$-level corpectomy $(\mathrm{n}=24,12 \%), 2$-level corpectomy $(n=9,5 \%), 3$-level corpectomy $(n=3,2 \%)$, 1-level corpectomy with 1-level ACDF ( $\mathrm{n}=6,3 \%)$, and 2-level corpectomy with 1-level ACDF $(\mathrm{n}=1,1 \%)$. The median levels fused were 2 (IQR 1.25). The mean dose of rhBMP-2 was $0.50 \pm 0.09 \mathrm{mg}$ per level (Table 2).

\section{Fusion Rate}

The fusion rate per number of levels fused was as follows: 1-level procedure, $96 \%(n=75 / 78)$; 2-level proce- 
TABLE 1. Baseline patient demographics

\begin{tabular}{lc}
\hline & Value \\
\hline No. of patients & 198 \\
\hline Mean age, yrs & $55 \pm 10$ \\
\hline Male sex & $95(48)$ \\
\hline Smoker & $62(31)$ \\
\hline NSAID & $15(8)$ \\
\hline Median CCI score [IQR] & $1[0-2]$ \\
\hline Mean length of follow-up, mos & $15 \pm 10$ \\
\hline
\end{tabular}

NSAID = nonsteroidal antiinflammatory drug.

Values represent the number of patients (\%) or mean \pm SD unless stated otherwise.

dure, $96 \%(n=68 / 71)$; 3-level procedure, 95\% $(n=39 / 41)$; and 4-level procedure, $100 \%(\mathrm{n}=8 / 8)$. The overall cohort fusion rate was $96 \%$. There was no difference in fusion rates between patients who were either smokers or nonsmokers ( $\mathrm{p}=0.7073$; Table 3$)$.

\section{Complications}

Twenty-two (11\%) patients experienced dysphagia. Of the patients with dysphagia, 6 (27\%) underwent a singlelevel procedure, $8(36 \%)$ underwent a 2-level procedure, $6(27 \%)$ underwent a 3-level procedure, and $2(10 \%)$ underwent a 4-level procedure. The incidence of dysphagia in single-level, 2-level, 3-level and 4-level procedures was $7.7 \%, 11.2 \%, 14.6 \%$, and $25 \%$, respectively. The greater the number of levels fused, the higher the incidence of dysphagia $(\mathrm{p}=0.012)$. No patients required a feeding tube at any point in their treatment. Eleven $(6 \%)$ patients experienced cervical swelling. Of the patients who experienced cervical swelling, 2 (18\%) underwent a single-level procedure, $8(73 \%)$ underwent a 2-level procedure, and $1(9 \%)$ underwent a 3-level procedure. There was no statistically

TABLE 2. Surgical characteristics

\begin{tabular}{lc}
\hline & Value \\
\hline ACDF & \\
\hline 1-level & $78(40)$ \\
\hline 2-level & $47(23)$ \\
\hline 3-level & $26(13)$ \\
\hline 4-level & $4(2)$ \\
\hline Corpectomy & $24(12)$ \\
\hline 1-level & $9(5)$ \\
\hline 2-level & $3(2)$ \\
\hline 3-level & $6(3)$ \\
\hline Combined & $1(1)$ \\
\hline 1-level corpectomy + 1-level ACDF & $2[1.25]$ \\
\hline 2-level corpectomy + 1-level ACDF & $0.50 \pm 0.09$ \\
\hline Median no. of levels fused [IQR] &
\end{tabular}

Values represent the number of patients (\%) or mean \pm SD unless stated otherwise.
TABLE 3. Fusion rate per level

\begin{tabular}{cc}
\hline & No. of Patients (\%) \\
\hline 1-level & $75(96)$ \\
\hline 2-level & $68(96)$ \\
\hline 3-level & $39(95)$ \\
\hline 4-level & $8(100)$ \\
\hline
\end{tabular}

significant difference in dysphagia rates or cervical swelling between device type, contained or noncontained, when comparing ACDF and corpectomy across levels. Three $(1.5 \%)$ patients experienced a postoperative hematoma, with 2 patients $(67 \%)$ requiring a return to the OR. Two $(1.0 \%)$ patients experienced a postoperative seroma, with 1 patient $(50 \%)$ requiring return to the OR for evacuation. Two (1\%) patients experienced pseudarthrosis requiring a posterior fusion. Three (2\%) patients experienced a new postoperative neurological deficit that had recovered by the last follow-up. There were no mortalities (Table 4).

\section{Discussion}

The use of rhBMP-2 in ACF is controversial and may be beneficial in select patients at high risk of developing pseudarthrosis. In this study, we set out to evaluate the safety and efficacy of low-dose rhBMP-2 for use in ACFs. As mentioned previously, the scientific literature is unclear about the safety and efficacy of using rhBMP-2 in ACF. The controversy involving rhBMP-2 is related to numerous reports and peer-reviewed publications citing an increase in soft-tissue-related complications. , $^{4,12-17}$ The most common complications reported in the scientific literature include dysphagia, cervical swelling, and hematoma/seroma formation.

Dysphagia is the most reported complication following ACF with rhBMP-2 augmentation. Several studies have reported statistically significant higher rates of dysphagia in rhBMP-2 groups versus control groups..$^{14,16,18-26}$ In a recent meta-analysis by Zadegan et al., ${ }^{17}$ the authors found a trend toward higher rates of dysphagia with rhBMP-2 in the pooled data (OR 1.75, CI 1.45-2.13; p < 0.0001), but statistical analysis was inconclusive because of substantial heterogeneity between the included studies, with an $\mathrm{I}^{2}=$ $76 \%$. In our study, the rate of dysphagia was $11 \%(22 / 198)$ at the last follow-up with no feeding tube requirements,

\section{TABLE 4. Complications}

\begin{tabular}{lc}
\hline & No. of Patients (\%) \\
\hline Dysphagia & $22(11)$ \\
\hline Cervical swelling & $11(6)$ \\
\hline Hematoma & $3(1.5)$ \\
\hline Seroma & $2(1)$ \\
\hline Return to OR & $3(2)$ \\
\hline Pseudarthrosis requiring posterior fusion & $2(1)$ \\
\hline Neurological deficit & $3(2)$ \\
\hline Death & $0(0)$ \\
\hline
\end{tabular}


which is similar to the incidence of dysphagia in $\mathrm{ACF}$ without rhBMP-2 in prospective evaluations. ${ }^{27,28}$

In our study, 6\% (11/198) of patients experienced cervical swelling. In the literature, several studies have reported higher swelling in rhBMP-2 groups than in control groups: Smucker et al. ${ }^{18}$ reported visible neck swelling in $2.9 \%$ [rhBMP-2 group] versus 0\% [control group]; Vaidya et al. ${ }^{20}$ reported swelling in $54.5 \%$ versus $0 \%$; Butterman ${ }^{29}$ reported swelling in 50\% versus $13.9 \%$; Frenkel et al. ${ }^{23}$ reported swelling in $4.5 \%$ versus $4.3 \%$; and Burkus et al. ${ }^{25}$ reported swelling in $3.6 \%$ versus $0.8 \%$. In our study we did not present a control group for comparison, but our rate of cervical swelling appeared to fall within the control group range of $0.0-13.9 \%$ in the aforementioned studies.

Interestingly, Maza et al..$^{30}$ showed that using a contained delivery device for rhBMP-2 significantly reduced postoperative swelling complications. For ACDF, J.P.M. used a contained delivery device, while E.A.P. used a noncontained device. On a level-by-level analysis, we found that there was no difference in dysphagia or cervical swelling when comparing ACDF using a contained device with ACDF using a noncontained device. This was evidence that our low-dose rhBMP-2 protocol may help reduce the incidence of postoperative complications because of a dose-dependent inflammatory process created by rhBMP-2 implantation. ${ }^{31}$

Seroma and hematoma formation occurs at a higher rate in rhBMP-2 groups than in controls in multiple studies and meta-analyses. ${ }^{2,14,17,24,32}$ Shields et al. ${ }^{4}$ reported that $15(10 \%)$ patients experienced hematoma, with 8 patients $(5 \%)$ requiring evacuation at an rhBMP-2 dose of $2.1 \mathrm{mg}$ per level. In our study, $3(1.5 \%)$ patients experienced hematoma formation with $2(1.0 \%)$ requiring a return to the OR for evacuation at an average rhBMP-2 dose of $0.5 \mathrm{mg}$ per level. Lu et al. ${ }^{16}$ reported a $2 \%$ reoperation rate for BMP-related seroma. In the present study, $2(1.0 \%)$ patients developed a BMP-related seroma, with $1(0.5 \%)$ requiring a return to the OR for BMP removal. Our results are similar to general hematoma formation for ACF without rhBMP-2. ${ }^{33}$

To our knowledge, this is the largest study evaluating the safety and efficacy of rhBMP-2 to date. The study results demonstrated decreased rates of dysphagia, cervical swelling, and seroma/hematoma formation with rhBMP-2 augmentation compared with the scientific literature of historical controls without the use of BMP. In addition, we reported no deaths or persistent neurological deficits. In our study, the average dose of rhBMP-2 was $0.50 \pm 0.09$ $\mathrm{mg}$ per level compared with $0.6-2.1 \mathrm{mg}$ per level used in the scientific literature. ${ }^{4,5,16,34,35}$ We believe that our lowdose protocol decreases morbidity associated with ACF rhBMP-2 usage while it successfully augments fusion without significant expense. In each case, either an $\mathrm{x}$-small or xx-small rhBMP-2 kit was used at a cost of $\$ 1905.00$ and $\$ 995.00$, respectively. Further studies are necessary to show the cost-effectiveness of the low-dose rhBMP-2 protocol. Smokers, the highest risk group for pseudarthrosis, ${ }^{36,37}$ had equivalent fusion rates compared with nonsmokers at the last follow-up. The overall 15-month fusion rate was $96 \%$. Furthermore, our rate of fusion was equivalent in 1-, 2-, 3-, and 4-level fusions. This is distinct from what is currently reported in the literature. ${ }^{38}$
The limitations inherent in our study resulted from its retrospective nature and lack of control group, and had implications for its interpretation. Retrospective studies are challenging given error due to confounding and bias. Future studies evaluating our low-dose rhBMP-2 protocol compared with a control group in a randomized controlled trial would be necessary to validate the results. The lack of a control group or multiple comparative groups utilizing varying doses of rhBMP-2 made it difficult to definitively conclude that our low-dose protocol was responsible for the decrease in complications compared with historical controls. Additionally, the lack of standardized dysphagia screening, such as the EAT-10 questionnaire (Nestlé Health Science), ${ }^{39}$ during this time period may mean we have not fully documented the degree of dysphagia in this population.

\section{Conclusions}

The use of low-dose rhBMP-2 safely and effectively augments anterior cervical arthrodesis. Our low-dose protocol appears to significantly reduce complications associated with rhBMP-2 use in ACF compared with the literature. Moreover, the use of low-dose rhBMP-2 in patients with multiple risk factors for pseudarthrosis appears to confer a high arthrodesis rate. We recommend using low-dose rhBMP-2 in patients who are smokers, those with multilevel ACFs, or others at high risk of developing pseudarthrosis.

\section{References}

1. Boden SD, Zdeblick TA, Sandhu HS, Heim SE. The use of rhBMP-2 in interbody fusion cages. Definitive evidence of osteoinduction in humans: a preliminary report. Spine (Phila Pa 1976). 2000;25(3):376-381.

2. Burkus JK, Gornet MF, Dickman CA, Zdeblick TA. Anterior lumbar interbody fusion using rhBMP-2 with tapered interbody cages. J Spinal Disord Tech. 2002;15(5):337-349.

3. Hofstetter CP, Hofer AS, Levi AD. Exploratory meta-analysis on dose-related efficacy and morbidity of bone morphogenetic protein in spinal arthrodesis surgery. $J$ Neurosurg Spine. 2016;24(3):457-475.

4. Shields LB, Raque GH, Glassman SD, et al. Adverse effects associated with high-dose recombinant human bone morphogenetic protein-2 use in anterior cervical spine fusion. Spine (Phila Pa 1976). 2006;31(5):542-547.

5. Tumialán LM, Pan J, Rodts GE, Mummaneni PV. The safety and efficacy of anterior cervical discectomy and fusion with polyetheretherketone spacer and recombinant human bone morphogenetic protein-2: a review of 200 patients. J Neurosurg Spine. 2008;8(6):529-535.

6. FDA Public Health Notification: Life-Threatening Complications Associated With Recombinant Human Bone Morphogenetic Protein in Cervical Spine Fusion. Food and Drug Administration; 2008.

7. Baskin DS, Ryan P, Sonntag V, et al. A prospective, randomized, controlled cervical fusion study using recombinant human bone morphogenetic protein-2 with the CORNERSTONE-SR allograft ring and the ATLANTIS anterior cervical plate. Spine (Phila Pa 1976). 2003;28(12):1219-1225.

8. Infuse Bone Graft Kit Components. Medtronic. Accessed April 12, 2021. https://www.medtronic.com/us-en/ healthcare-professionals/products/spinal-orthopaedic/bonegrafting/infuse-bone-graft.html

9. Ploumis A, Mehbod A, Garvey T, et al. Prospective assess- 
ment of cervical fusion status: plain radiographs versus CTscan. Acta Orthop Belg. 2006;72(3):342-346.

10. Cannada LK, Scherping SC, Yoo JU, et al. Pseudoarthrosis of the cervical spine: a comparison of radiographic diagnostic measures. Spine (Phila Pa 1976). 2003;28(1):46-51.

11. Epstein NE, Silvergleide RS. Documenting fusion following anterior cervical surgery: a comparison of roentgenogram versus two-dimensional computed tomographic findings. $J$ Spinal Disord Tech. 2003;16(3):243-247.

12. Hustedt JW, Blizzard DJ. The controversy surrounding bone morphogenetic proteins in the spine: a review of current research. Yale J Biol Med. 2014;87(4):549-561.

13. Perri B, Cooper M, Lauryssen C, Anand N. Adverse swelling associated with use of rh-BMP-2 in anterior cervical discectomy and fusion: a case study. Spine J. 2007;7(2):235-239.

14. Fineberg SJ, Ahmadinia K, Oglesby M, et al. Hospital outcomes and complications of anterior and posterior cervical fusion with bone morphogenetic protein. Spine (Phila Pa 1976). 2013;38(15):1304-1309.

15. Singh K, Marquez-Lara A, Nandyala SV, et al. Incidence and risk factors for dysphagia after anterior cervical fusion. Spine (Phila Pa 1976). 2013;38(21):1820-1825.

16. Lu DC, Tumialán LM, Chou D. Multilevel anterior cervical discectomy and fusion with and without rhBMP-2: a comparison of dysphagia rates and outcomes in 150 patients. $J$ Neurosurg Spine. 2013;18(1):43-49.

17. Zadegan SA, Abedi A, Jazayeri SB, et al. Bone morphogenetic proteins in anterior cervical fusion: a systematic review and meta-analysis. World Neurosurg. 2017;104:752-787.

18. Smucker JD, Rhee JM, Singh K, et al. Increased swelling complications associated with off-label usage of rhBMP-2 in the anterior cervical spine. Spine (Phila Pa 1976). 2006; 31(24):2813-2819.

19. Vaidya R, Carp J, Sethi A, et al. Complications of anterior cervical discectomy and fusion using recombinant human bone morphogenetic protein-2. Eur Spine J. 2007;16(8): $1257-1265$.

20. Vaidya R, Weir R, Sethi A, et al. Interbody fusion with allograft and rhBMP-2 leads to consistent fusion but early subsidence. J Bone Joint Surg Br. 2007;89(3):342-345.

21. Cahill KS, Chi JH, Day A, Claus EB. Prevalence, complications, and hospital charges associated with use of bonemorphogenetic proteins in spinal fusion procedures. JAMA. 2009;302(1):58-66.

22. Williams BJ, Smith JS, Fu KM, et al. Does bone morphogenetic protein increase the incidence of perioperative complications in spinal fusion? A comparison of 55,862 cases of spinal fusion with and without bone morphogenetic protein. Spine (Phila Pa 1976). 2011;36(20):1685-1691.

23. Frenkel MB, Cahill KS, Javahary RJ, et al. Fusion rates in multilevel, instrumented anterior cervical fusion for degenerative disease with and without the use of bone morphogenetic protein. J Neurosurg Spine. 2013;18(3):269-273.

24. Cole T, Veeravagu A, Jiang B, Ratliff JK. Usage of recombinant human bone morphogenetic protein in cervical spine procedures: analysis of the MarketScan longitudinal database. J Bone Joint Surg Am. 2014;96(17):1409-1416.

25. Burkus JK, Dryer RF, Arnold PM, Foley KT. Clinical and radiographic outcomes in patients undergoing single-level anterior cervical arthrodesis: a prospective trial comparing allograft to a reduced dose of rhBMP-2. Clin Spine Surg. 2017;30(9):E1321-E1332.

26. Poeran J, Opperer M, Rasul R, et al. Change in off-label use of bone morphogenetic protein in spine surgery and associations with adverse outcome. Global Spine J. 2016;6(7):650-659.

27. Opsenak R, Kolarovszki B, Benco M, et al. Dysphagia after anterior cervical discectomy and interbody fusion - prospective study with 1-year follow-up. Rozhl Chir. 2019;98(3): $115-120$.
28. Bazaz R, Lee MJ, Yoo JU. Incidence of dysphagia after anterior cervical spine surgery: a prospective study. Spine (Phila Pa 1976). 2002;27(22):2453-2458.

29. Buttermann GR. Prospective nonrandomized comparison of an allograft with bone morphogenic protein versus an iliaccrest autograft in anterior cervical discectomy and fusion. Spine J. 2008;8(3):426-435.

30. Maza NM, Ferrer CE, Qureshi SA, et al. Contained-delivery route and the administration of postoperative steroids following anterior cervical spinal fusion with low-dose rhBMP-2 reduces the magnitude of respiratory compromise. Clin Spine Surg. 2019;32(10):E420-E425.

31. Lee KB, Taghavi CE, Song KJ, et al. Inflammatory characteristics of rhBMP-2 in vitro and in an in vivo rodent model. Spine (Phila Pa 1976). 2011;36(3):E149-E154.

32. Jain A, Hassanzadeh $\mathrm{H}$, Strike SA, et al. rhBMP use in cervical spine surgery: associated factors and in-hospital complications. J Bone Joint Surg Am. 2014;96(8):617-623.

33. Bovonratwet $\mathrm{P}, \mathrm{Fu} \mathrm{MC}$, Tyagi $\mathrm{V}$, et al. Incidence, risk factors, and clinical implications of postoperative hematoma requiring reoperation following anterior cervical discectomy and fusion. Spine (Phila Pa 1976). 2019;44(8):543-549.

34. Arnold PM, Anderson KK, Selim A, et al. Heterotopic ossification following single-level anterior cervical discectomy and fusion: results from the prospective, multicenter, historically controlled trial comparing allograft to an optimized dose of rhBMP-2. J Neurosurg Spine. 2016;25(3):292-302.

35. Tan B, Wang H, Dong J, et al. Comparison of rhBMP-2 versus autogenous iliac crest bone graft for 2-level anterior cervical discectomy and fusion for cervical spondylotic myelopathy. Med Sci Monit. 2015;21:3159-3165.

36. Hilibrand AS, Fye MA, Emery SE, et al. Impact of smoking on the outcome of anterior cervical arthrodesis with interbody or strut-grafting. J Bone Joint Surg Am. 2001;83(5): 668-673.

37. Lau D, Chou D, Ziewacz JE, Mummaneni PV. The effects of smoking on perioperative outcomes and pseudarthrosis following anterior cervical corpectomy: clinical article. $J \mathrm{Neu}$ rosurg Spine. 2014;21(4):547-558.

38. Fraser JF, Härtl R. Anterior approaches to fusion of the cervical spine: a metaanalysis of fusion rates. J Neurosurg Spine. 2007;6(4):298-303.

39. Belafsky PC, Mouadeb DA, Rees CJ, et al. Validity and reliability of the Eating Assessment Tool (EAT-10). Ann Otol Rhinol Laryngol. 2008;117(12):919-924.

\section{Disclosures}

Dr. Potts: royalties from and consultant for Medtronic.

\section{Author Contributions}

Conception and design: all authors. Acquisition of data: all authors. Analysis and interpretation of data: all authors. Drafting the article: all authors. Critically revising the article: all authors. Reviewed submitted version of manuscript: all authors. Study supervision: Potts, Mendenhall.

\section{Supplemental Information \\ Videos}

Video Abstract. https://vimeo.com/547434516.

\section{Correspondence}

Eric A. Potts: Goodman Campbell Brain and Spine, Carmel, IN. epotts@goodmancampbell.com. 